\title{
Relationship between body composition indicators and risk of type 2 diabetes mellitus in Chinese adults
}

Yongchun Chen ${ }^{1+}$, Dongliang He ${ }^{2 \dagger}$, Tingting Yang ${ }^{1}, \mathrm{Hao}_{\text {Zhou }}^{3}$, Siyun Xiang ${ }^{1}$, Lijun Shen ${ }^{4}$, Jing Wen ${ }^{1}$, Shengcai Chen ${ }^{5^{*}}$, Songxu Peng ${ }^{6^{*}}$ and Yong Gan ${ }^{7^{*}}$

\begin{abstract}
Background: Body composition is a crucial factor associated with the incidence of type 2 diabetes mellitus. However, no study on this relationship has been performed in the Chinese population. This study aimed to investigate the relationship between body composition indicators and risk of type 2 diabetes mellitus among Chinese adults undergoing medical examination.
\end{abstract}

Methods: Between January 2018 and July 2018, a retrospective cross-sectional study was performed on 3367 (2307 male and 1060 female) participants aged $\geq 18$ years undergoing medical examination in Zhengzhou. Logistic regression analysis was performed to explore the relationship between body composition indicators and risk of type 2 diabetes mellitus. A receiver operating characteristic curve was used to calculate cutoff points and the predictive power of each indicator.

Results: Among the 3367 participants, 12.53\% were diagnosed with type 2 diabetes mellitus. Multivariate logistic analysis indicated that male participants (odds ratio $[\mathrm{OR}]=1.68,95 \%$ confidence interval [Cl]: 1.29-2.19), older participants $(\mathrm{OR}=1.05,95 \% \mathrm{Cl}: 1.04-1.06)$, participants with a waist-to-hip ratio above the reference value (OR=1.56, 95\% Cl: 1.18-2.07), participants with body fat percentage above the reference value (OR=1.62, 95\% Cl: $1.01-2.68)$, and participant with a large visceral fat area $(\mathrm{OR}=1.01,95 \% \mathrm{Cl}: 1.01-1.02)$ had a high risk of type 2 diabetes mellitus. Waistto-hip ratio, body fat percentage, and visceral fat area were the best indicators of type 2 diabetes mellitus $(P<0.001)$ with cutoff values of $0.90,25.02 \%$, and $92.00 \mathrm{~cm}^{2}$, respectively.

(Continued on next page)

\footnotetext{
*Correspondence: 1912956494@qq.com; gwxypsx@163.com; scswj2008@163.com

${ }^{\dagger}$ Yongchun Chen and Dongliang He contributed equally to this work. ${ }^{5}$ Department of Neurology, Union Hospital, Tongji Medical College, Huazhong University of Science and Technology, No. 1277 Jiefang Avenue, Wuhan 430022, Hubei, People's Republic of China

${ }^{6}$ Department of Maternal and Child Health, Xiangya School of Public Health, Central South University, No. 110, Xiangya Road, Changsha 410008, People's Republic of China

${ }^{7}$ Department of Social Medicine and Health Management, School of Public Health, Tongji Medical College, Huazhong University of Science and Technology, No. 13 Hangkong Road, Wuhan, Hubei 430030, People's Republic of China

Full list of author information is available at the end of the article
}

(c) The Author(s). 2020 Open Access This article is licensed under a Creative Commons Attribution 4.0 International License, which permits use, sharing, adaptation, distribution and reproduction in any medium or format, as long as you give appropriate credit to the original author(s) and the source, provide a link to the Creative Commons licence, and indicate if changes were made. The images or other third party material in this article are included in the article's Creative Commons licence, unless indicated otherwise in a credit line to the material. If material is not included in the article's Creative Commons licence and your intended use is not permitted by statutory regulation or exceeds the permitted use, you will need to obtain permission directly from the copyright holder. To view a copy of this licence, visit http://creativecommons.org/licenses/by/4.0/. The Creative Commons Public Domain Dedication waiver (http://creativecommons.org/publicdomain/zero/1.0/) applies to the data made available in this article, unless otherwise stated in a credit line to the data. 
(Continued from previous page)

Conclusion: This study suggests a predictive relationship between type 2 diabetes mellitus and body composition indicators of waist-to-hip ratio, body fat percentage, and visceral fat area, which are valuable for screening diabetes and providing effective health education and behavioral intervention for high-risk populations.

Keywords: Body composition, Type 2 diabetes mellitus, Predictive value, Indicators, Visceral fat area

\section{Background}

Diabetes is a condition that results from defective regulation of blood glucose, resulting in increased blood glucose levels [1-3]. Type 2 diabetes mellitus (T2DM) is the most common form of diabetes, accounting for approximately 90\% of diabetes cases. The 2017 International Diabetes Federation (IDF) report showed that the number of diabetes patients in China reached 114.4 million in 2017, with 61.3 million (53.6\%) newly diagnosed patients [4].

The increased incidence of T2DM has been linked to several risk factors, including population aging, economic development, urbanization, and obesity due to sedentary lifestyles and excessive eating [5-7]. Excessive accumulation of visceral fat leads to an imbalance in endocrine function and the release of pro-inflammatory factors, which may result in the development of insulin resistance and T2DM [8, 9]. Therefore, it is important to explore an effective measurement method to assess obesity-especially abdominal obesity-for early diagnosis and treatment of diabetes. Previous studies have explored body mass index (BMI), waist circumference, waist-to-hip ratio, and waist-to-height ratio as measures of obesity [10-12]. However, these measures are limited in their assessment of body composition and lack sensitivity in diagnosing T2DM. Recently, bioelectrical impedance analysis (BIA) has been developed to measure body composition [13], which has been shown to be a more convenient and less invasive method for assessing abdominal obesity and fat distribution.

Although there have been various epidemiological studies to determine the association between body composition indicators and risk of T2DM in other countries [14-16], no such study has been performed in China, the most populated country in the world.

This study aimed to investigate the relationship between body composition indicators and the risk of T2DM in Chinese adults undergoing medical examination. In addition, the receiver operating characteristic (ROC) curve was used to determine the best cutoff value of body composition indicators. These findings will not only provide a reference for T2DM screening and primary means for prevention but also enrich the research pool within the field of diabetes.

\section{Material}

\section{Study population}

The data of 3367 (2307 male and 1060 female) participants who underwent medical screening conducted between January 2018 and July 2018 at a tertiary hospital in Henan Province, China, were retrospectively analyzed. The participants were included if they met the following criteria: (1) aged $\geq 18$ years and (2) examination of body composition using the BIA. The following participants were excluded from the study: those with (1) a history of chronic liver and kidney disease, thyroid disease, parathyroid disease, cancers, and type 1 diabetes; (2) a history of taking steroids; and (3) a history of taking hormonal agents. The inclusion/exclusion information was obtained from medical records and pre-examination inquiries.

\section{Measurement methods Blood glucose}

A total of $2 \mathrm{~mL}$ of venous blood was collected in the fasted state. Blood glucose level was then measured with a glucometer. According to the IDF Diabetes Atlas (8th Edition, 2017), the diagnostic criteria for diabetes were as follows: (1) fasting blood glucose $\geq 7.0 \mathrm{mmol} / \mathrm{L}$ (126 mg/dL), (2) blood glucose $2 \mathrm{~h}$ after the 75 -g oral glucose tolerance test $\geq 11.1 \mathrm{mmol} / \mathrm{L}(200 \mathrm{mg} / \mathrm{dL})$, (3) random blood glucose $>11.1 \mathrm{mmol} / \mathrm{L}(200 \mathrm{mg} / \mathrm{dL})$, and (4) fulfillment of any one of the three criteria mentioned above or prior history of diabetes [4].

\section{Body composition analysis}

Body composition was measured by BIA using the InBody 770 (InBody Co., Ltd., Seoul, Korea), which consists of a patented 8-point tactile electrode system that estimates segmental composition, including body water, muscle mass, waist-to-hip ratio, body fat percentage, and visceral fat area (VFA). This widely used measurement is safe, non-invasive, and highly precise with comprehensive indicators and short measurement time [17]. Before the examination, the participants were required to empty their bowels and bladder, maintain a fasted state, wear light clothes, expose their limbs for electrode attachment, and rest for $5 \mathrm{~min}$ to ensure that accurate measurements were captured.

\section{Judgment standards}

The participants were deemed to have T2DM if they had a fasting blood glucose level of $\geq 7.0 \mathrm{mmol} / \mathrm{L}$ (126 $\mathrm{mg} / \mathrm{dL}$ ), if they had a $2 \mathrm{~h}$ postprandial blood glucose level of $>11.1 \mathrm{mmol} / \mathrm{L}(200 \mathrm{mg} / \mathrm{dL})$, or in cases of selfreported diabetes [18]. Waist-to-hip ratio was classified as normal or over-standard with cutoff levels for normal 
classification at 0.9 for males and 0.8 for females [19]. The normal range of body fat percentages in males and females was $10-20 \%$ and $18-28 \%$, respectively. On the basis of the criteria for overweight and obesity reported by the Working Group on Obesity in China, a BMI of $\geq 24.0 \mathrm{~kg} / \mathrm{m}^{2}$ was considered to indicate overweight or obesity and a BMI of $<24.0 \mathrm{~kg} / \mathrm{m}^{2}$ was considered normal or low [20]. All the participants were classified into normal/low or over-standard groups.

\section{Statistical analysis}

Mean \pm standard deviation was used for continuous variables, while counts and percentages were used for categorical data. Student's $t$-test and the Chi-square test were applied to examine the differences in T2DM and its subscales among groups. Multiple logistic regression analysis was performed to estimate the predictors of T2DM. The area under the ROC curve was used to predict the optimal cutoff point for T2DM. Statistical analysis was performed using IBM statistics (SPSS) V.17. The significance level was set at $\alpha=0.05$.

\section{Results}

Overall, 3367 participants were included in the study: $2307(68.52 \%)$ males and 1060 (31.48\%) females. The average age of the participants was $52.57 \pm 15.61$ years. In total, 1974 participants $(58.63 \%)$ were deemed overweight or obese $\left(\mathrm{BMI} \geq 24.0 \mathrm{~kg} / \mathrm{m}^{2}\right)$. In the overstandard group, there were 2477 (73.57\%) and 2909 (86.40\%) participants, on the basis of their waist-to-hip ratio and body fat percentage, respectively. The average VFA of the participants was $94.76 \pm 34.01 \mathrm{~cm}^{2}$. Among the participants, $12.53 \%$ were diagnosed with T2DM (Table 1).

Differences in the indicators among participants with and without T2DM were analyzed by the chi-square test and independent sample $t$-test. The results showed that the detection rate of T2DM was higher for males than for females $\left(14.35 \%\right.$ vs. $\left.8.58 \%, X^{2}=22.00, P<0.001\right)$. The mean age was higher in theT2DM group than in the noT2DM group $(63.02 \pm 13.21$ years vs. $51.07 \pm 15.35$ years, $\mathrm{t}=14.76, P<0.001)$. The frequency of waist-to-hip ratio above the reference value $(13.85 \%)$, obesity or overweight by BMI (14.74\%), body fat percentage above the reference value (13.78\%), and mean VFA $(104.60 \pm 34.71$ $\mathrm{cm}^{2}$ ) was higher in the T2DM group than in the noT2DM group. The differences were all statistically significant $(P<0.05)$ (Table 2).

After adjusting for age and sex, the results of logistic regression analysis for risk factors of T2DM showed that the over-standard waist-to-hip ratio (odds ratio $[\mathrm{OR}]=$ $1.56,95 \%$ confidence interval $[\mathrm{CI}]: 1.18-2.07, P=0.002)$, body fat percentage above the reference value $(\mathrm{OR}=$ 1.62, 95\% CI: $1.01-2.68, P=0.049)$, and large VFA (OR $=$
Table 1 General situation analysis of medical examination population

\begin{tabular}{|c|c|c|}
\hline Characteristics & Number (n) & Percentage (\%) \\
\hline \multicolumn{3}{|l|}{ Sex } \\
\hline Males & 2307 & 68.52 \\
\hline Females & 1060 & 31.48 \\
\hline $\operatorname{Age}(\bar{x} \pm s$, years $)$ & $52.57 \pm 15.61$ & \\
\hline \multicolumn{3}{|l|}{ BMI } \\
\hline$<24.0 \mathrm{~kg} / \mathrm{m}^{2}$ & 1393 & 41.37 \\
\hline$\geq 24.0 \mathrm{~kg} / \mathrm{m}^{2}$ & 1974 & 58.63 \\
\hline \multicolumn{3}{|l|}{ Waist-to-hip ratio } \\
\hline Normal & 890 & 26.43 \\
\hline Over-standard & 2477 & 73.57 \\
\hline \multicolumn{3}{|l|}{ Body fat percentage } \\
\hline Normal or under & 458 & 13.60 \\
\hline Over-standard & 2909 & 86.40 \\
\hline $\operatorname{VFA}\left(\bar{x} \pm s, \mathrm{~cm}^{2}\right)$ & $94.76 \pm 34.01$ & \\
\hline \multicolumn{3}{|l|}{ Type 2 diabetes } \\
\hline Yes & 422 & 12.53 \\
\hline No & 2945 & 87.47 \\
\hline
\end{tabular}

Abbreviations: BMI body mass index, VFA visceral fat area

1.01, 95\% CI: $1.01-1.02, P=0.001)$ are important predictors of T2DM (Table 3).

The ROC curves of the significant body composition indicators (waist-to-hip ratio, body fat percentage, VFA) from regression analysis were used to further determine the predictive effect of those indicators on T2DM. According to the ROC curves, the waist-to-hip ratio, body fat percentage, and VFA had predictive effects on T2DM $(P<0.001)$ among all participants with predictive cutoff values of $0.90,25.02 \%$, and $92.00 \mathrm{~cm}^{2}$, respectively. Among male participants, the predictive effects of waistto-hip ratio, body fat percentage, and VFA on T2DM were statistically significant $(P<0.05)$ with predictive cutoff values $0.93,25.02 \%$, and $74.15 \mathrm{~cm}^{2}$, respectively. Among female participants, the predictive effects of waist-to-hip ratio, body fat percentage, and VFA on T2DM were statistically significant $(P<0.05)$ with predictive cutoff values of $0.89,36.60 \%$, and $90.15 \mathrm{~cm}^{2}$, respectively (Table 4).

\section{Discussion}

Diabetes is the third leading cause of death worldwide, posing a serious threat to human health and exerting a heavy burden on patients, patients' families, and society [21-23]. Epidemiological studies have shown that effective prevention and control of T2DM can have enormous social and economic benefits by delaying or reducing the onset of disease and related complications [24]. The participants in this study were a group of people 
Table 2 Comparison of relevant indicators between participants with and without T2DM

\begin{tabular}{|c|c|c|c|c|}
\hline Variables & With T2DM & Without T2DM & $x^{2} / t$ & $P$ \\
\hline $\operatorname{Sex}(n, \%)$ & & & 22.00 & $<0.001$ \\
\hline Males & $331(14.35)$ & $1976(85.65)$ & & \\
\hline Females & $91(8.58)$ & $969(91.42)$ & & \\
\hline $\operatorname{Age}(\bar{x} \pm s$, years $)$ & $63.02 \pm 13.21$ & $51.07 \pm 15.35$ & 17.02 & $<0.001$ \\
\hline \multicolumn{2}{|c|}{ Waist-to-hip ratio (n, \%) } & & 14.76 & $<0.001$ \\
\hline Normal & 79 (8.88) & 811 (91.12) & & \\
\hline Over-standard & $343(13.85)$ & $2134(86.15)$ & & \\
\hline BMI $(n, \%)$ & & & 21.22 & $<0.001$ \\
\hline$<24.0 \mathrm{~kg} / \mathrm{m}^{2}$ & $131(9.40)$ & $1262(90.60)$ & & \\
\hline$\geq 24.0 \mathrm{~kg} / \mathrm{m}^{2}$ & $291(14.74)$ & $1683(85.26)$ & & \\
\hline \multicolumn{2}{|c|}{ Body fat percentage $(n, \%)$} & & 30.55 & $<0.001$ \\
\hline Normal or under & $21(4.59)$ & 437 (95.41) & & \\
\hline Over-standard & $401(13.78)$ & $2508(86.22)$ & & \\
\hline $\operatorname{VFA}\left(\bar{x} \pm s, \mathrm{~cm}^{2}\right)$ & $104.60 \pm 34.71$ & $93.34 \pm 33.67$ & 6.40 & $<0.001$ \\
\hline
\end{tabular}

Abbreviations: $B M I$ body mass index, VFA visceral fat area

undergoing medical examination in a Grade A Class 3 hospital in Henan Province. The prevalence of T2DM was $12.53 \%$ in this study, which was higher than the prevalence reported by Yang W et al. in 2007, i.e., 9.7\% [25] and closer to the prevalence reported by $\mathrm{Xu} \mathrm{Y}$ et al. in 2010, i.e., $11.6 \%$ [26]. This difference may be due to the different screening conditions of participants.

T2DM is known to have an insidious onset and can easily lead to serious complications that threaten human health. Accelerated rhythm of life, unhealthy diet, and sedentary lifestyle lead to storage of excess nutrients in the body and changes in body composition, resulting in metabolic disturbances [27]. Studying the relationship between body composition and T2DM is thus beneficial, as measurements of body composition can enable timely and effective identification of risk factors for T2DM, facilitating its early prevention.
Logistic regression analysis showed that male sex, old age, waist-to-hip ratio over the reference value, body fat percentage over the reference value, and large VFA were positively correlated with T2DM. The prevalence rate of T2DM was 1.68 times higher in males than in females, likely due to differences in lifestyle and work stress $[25,26]$. In addition, the risk of T2DM increased because of changes in metabolism related to old age. Old age has become one of the established risk factors for T2DM. The results showed that while waist-to-hip ratio, body fat percentage, and VFA were associated with T2DM, BMI was not significantly associated with it. This suggested that the accumulation of abdominal fat is positively correlated with the onset of T2DM, and future research must explore the relationship between abdominal obesity and T2DM on a larger scale.

The ROC curve was used to evaluate the predictive value of various body composition indicators associated with the risk of T2DM. The average age of the study population was $52.57 \pm 15.61$ years. Because of differences in physiological changes and metabolism between males and females, in this study, we conducted a sexbased analysis apart from the overall population study to clearly show the risk factors of T2DM across sexes. Among all participants, the waist-to-hip ratio had a stronger predictive effect on T2DM with an optimal cutoff value of 0.90 . Among male participants, the waist-tohip ratio and body fat percentage showed strong predictive effects with optimal cutoff values of 0.93 and $25.02 \%$, respectively. The predictive effect of the waist-to-hip ratio on T2DM in the male population suggests an adverse risk of abdominal obesity in males. Reducing abdominal fat accumulation may reduce the occurrence and development of male T2DM.

Among female participants, VFA had the strongest predictive effect on T2DM with a cutoff point of $90.15 \mathrm{~cm}^{2}$, which was lower than the previous VFA cutoff value i.e.

Table 3 Logistic regression analysis of risk factors of T2DM in medical examination population

\begin{tabular}{|c|c|c|c|c|c|}
\hline Characteristics & $\beta$ & $S E$ & Wald & OR $(95 \% C l)^{\text {a }}$ & $P$-value \\
\hline Constant term & -7.82 & 0.59 & 177.87 & & $<0.001$ \\
\hline \multicolumn{6}{|c|}{ Sex (Females as a reference) } \\
\hline Males & 0.52 & 0.14 & 14.84 & $1.68(1.29-2.19)$ & $<0.001$ \\
\hline Age (years) & 0.05 & 0.00 & 168.55 & $1.05(1.04-1.06)$ & $<0.001$ \\
\hline \multicolumn{6}{|c|}{ Waist-to-hip ratio (normal as a reference) } \\
\hline Over-standard & 0.45 & 0.14 & 9.84 & $1.56(1.18-2.07)$ & 0.002 \\
\hline \multicolumn{6}{|c|}{ Body fat percentage (normal or low as a reference) } \\
\hline Over-standard & 0.48 & 0.26 & 3.60 & $1.62(1.01-2.68)$ & 0.049 \\
\hline VFA $\left(\mathrm{cm}^{2}\right)$ & 0.01 & 0.00 & 11.23 & $1.01(1.01-1.02)$ & 0.001 \\
\hline
\end{tabular}

Abbreviations: $O R$ odds ratio, VFA visceral fat area, $C l$ confidence interval, T2DM type 2 diabetes mellitus ${ }^{\mathrm{a} O R}$ adjusted for BMI 
Table 4 Analysis of the predictive effect of body composition indicators on T2DM

\begin{tabular}{lllllllll}
\hline Body composition index & Classification & AUC & $\boldsymbol{P}$ & AUC95\% Cl & Cutoff points & Sensitivity & Specificity & Youden index \\
\hline Waist-to-hip ratio & All & $0.60 \pm 0.02$ & $<0.001$ & $0.58-0.63$ & 0.90 & 0.706 & 0.458 & 0.164 \\
& Males & $0.58 \pm 0.02$ & $<0.001$ & $0.54-0.61$ & 0.93 & 0.544 & 0.598 & 0.142 \\
& Females & $0.63 \pm 0.03$ & $<0.001$ & $0.58-0.69$ & 0.89 & 0.582 & 0.628 & 0.210 \\
Body fat percentage(\%) & All & $0.55 \pm 0.01$ & 0.001 & $0.52-0.58$ & 25.02 & 0.810 & 0.273 & 0.083 \\
& Males & $0.58 \pm 0.02$ & $<0.001$ & $0.54-0.61$ & 25.02 & 0.767 & 0.359 & 0.126 \\
VFA $\left(\mathrm{cm}^{2}\right)$ & Females & $0.66 \pm 0.03$ & $<0.001$ & $0.60-0.71$ & 36.60 & 0.516 & 0.739 & 0.255 \\
& All & $0.60 \pm 0.01$ & $<0.001$ & $0.57-0.62$ & 92.00 & 0.600 & 0.540 & 0.140 \\
& Males & $0.58 \pm 0.02$ & $<0.001$ & $0.55-0.61$ & 74.15 & 0.819 & 0.303 & 0.122 \\
& Females & $0.67 \pm 0.03$ & $<0.001$ & $0.62-0.73$ & 90.15 & 0.813 & 0.464 & 0.277 \\
\hline
\end{tabular}

Abbreviations: $A U C$ area under curve, $C I$ confidence interval, $S D$ standard deviation, VFA visceral fat area, T2DM type 2 diabetes mellitus

$100 \mathrm{~cm}^{2}$ [28]. The lower predictive cutoff value may be attributed to population diversity. Among all body composition indicators, body fat percentage and VFA showed the strongest predictive effects on T2DM. Monitoring body composition indicators, specifically body fat percentage and VFA, can help identify underlying obesity in a timely manner, which is of great significance for reducing the onset and complications of T2DM.

This study has some limitations. First, this study was a cross-sectional study design, which restricted the predictive effect of the temporality and causality of the observed relationships. Second, the participants were selected from the medical examination population in one hospital, thus making selection bias unavoidable. Third, other potential predictors of T2DM (socioeconomic status, history of chronic disease, etc.) were not studied in our research. In the future, multi-center cohort studies, covering populations from different regions and including more influential factors, should be considered to verify the results of this study.

\section{Conclusions}

The results of this study showed a high prevalence rate of T2DM associated with body composition indicators. Age, sex, waist-to-hip ratio, body fat percentage, and VFA were independent risk factors for T2DM. Waist-tohip ratio and VFA had strong predictive effects on T2DM. The comprehensive measurement of human body composition and associated risk assessment system could provide an important diagnostic tool for individualized prevention of T2DM.

\section{Abbreviations}

AUC: Area under curve; BMl: Body mass index; Cl: Confidence interval; HbA1c: Hemoglobin A1c; OR: Odds ratio; ROC: Receiver operating characteristic; SD: Standard deviation; VFA: Visceral fat area; T2DM: Type 2 diabetes mellitus

\section{Acknowledgments}

All the authors would like to extend gratitude to the participants, all staff members involved in this study for their painstaking efforts in conducting the data collection.

\section{Authors' contributions}

Y.G., S.X.P. and S.C.C. conceived and designed the study. Y.C.C., D.L.H., T.T.Y., H.Z., S.Y.X., J.W. and L.J.S. participated in the acquisition of data. T.T.Y. analyzed the data. Y.G., S.X.P. and S.Y.X. gave advice on methodology. Y.C.C. and H.Z. wrote the draft of the paper. All authors contributed to writing, reviewing or revising the paper and read and approved the final manuscript. Y.G. is the guarantor of this work and had full access to all the data in the study and takes responsibility for its integrity and the accuracy of the data analysis.

\section{Funding}

This study was approved by the China Postdoctoral Science Foundation funded project (2019 M652544). The funder had no role in the study design, data collection and analysis, decision to publish, or preparation of the manuscript. Informed consent was obtained from all survey participants.

\section{Availability of data and materials}

Data may be made available by contacting the corresponding author on reasonable request with permission from Y.G.

\section{Ethics approval and consent to participate}

All individuals provided written informed consent, and this study protocol was approved by the institutional review boards of The People's Hospital of Henan Province (Zhengzhou, China).

\section{Consent for publication}

Not applicable.

\section{Competing interests}

The authors declare that they have no competing interests.

\section{Author details}

'Department of Nutrition, Henan Provincial People's Hospital and Zhengzhou University People's Hospital, Zhengzhou, Henan 450003, People's Republic of China. ${ }^{2}$ Department of Nutrition, Hengyang Central Hospital, Hengyang, Hunan 421001, People's Republic of China. ${ }^{3}$ Department of Medical Record, Fuwai Central China Cardiovascular Hospital, Zhengzhou, Henan 451464, People's Republic of China. ${ }^{4}$ Department of Research and Discipline Development, Henan Provincial People's Hospital and Zhengzhou University People's Hospital, Zhengzhou 450003, People's Republic of China.

${ }^{5}$ Department of Neurology, Union Hospital, Tongji Medical College, Huazhong University of Science and Technology, No. 1277 Jiefang Avenue, Wuhan 430022, Hubei, People's Republic of China. ${ }^{6}$ Department of Maternal and Child Health, Xiangya School of Public Health, Central South University, No. 110, Xiangya Road, Changsha 410008, People's Republic of China.

${ }^{7}$ Department of Social Medicine and Health Management, School of Public 
Health, Tongji Medical College, Huazhong University of Science and Technology, No. 13 Hangkong Road, Wuhan, Hubei 430030, People's Republic of China.

Received: 29 November 2019 Accepted: 18 March 2020

Published online: 06 April 2020

\section{References}

1. Evans JM, Newton RW, Ruta DA, et al. Socio-economic status, obesity and prevalence of type 1 and type 2 diabetes mellitus. Diabet Med. 2000;17(6): 478-80

2. Bruno G, Runzo C, Cavallo-Perin P, et al. Incidence of type 1 and type 2 diabetes in adults aged 30-49 years: the population-based registry in the province of Turin, Italy. Diabetes Care. 2005;28(11):2613-9.

3. Holman N, Young B, Gadsby R. Current prevalence of type 1 and type 2 diabetes in adults and children in the UK. Diabet Med. 2015;32(9):1119-20.

4. International Diabetes Federation. IDF Diabetes Atlas. Eight edition. 2017 https://www.idf.org/e-library/epidemiology-research/diabetes-atlas/134-idfdiabetes-atlas-8th-edition.html.

5. Mozaffarian D. Dietary and policy priorities for cardiovascular disease, diabetes, and obesity: a comprehensive review. Circulation. 2016;133(2):187225.

6. Forouhi NG, Wareham NJ. The EPIC-InterAct study: a study of the interplay between genetic and lifestyle behavioral factors on the risk of type 2 diabetes in European populations. Curr Nutr Rep. 2014;3(4):355-63.

7. Ley SH, Hamdy O, Mohan V , et al. Prevention and management of type 2 diabetes: dietary components and nutritional strategies. Lancet. 2014; 383(9933):1999-2007.

8. Lv X, Zhou W, Sun J, Lin R, Ding L, Xu M, et al. Visceral adiposity is significantly associated with type 2 diabetes in middle-aged and elderly Chinese women: a cross-sectional study. J Diabetes. 2017;9(10):920-8.

9. Bays HE. Adiposopathy is "sick fat" a cardiovascular disease? J Am Coll Cardiol. 2011;57(25):2461-73.

10. Bertrand LA, Thomas LJ, Li $P$, et al. Obesity as defined by waist circumference but not body mass index is associated with higher renal mass complexity. Urol Oncol. 2017;35(11):661.e1-6.

11. Borel AL, Coumes S, Reche F, et al. Waist, neck circumferences, waist-to-hip ratio: which is the best cardiometabolic risk marker in women with severe obesity? The SOON cohort. PLoS One. 2018;13(11):e0206617.

12. Liu L, Wang $Y$, Zhang W, et al. Waist height ratio predicts chronic kidney disease: a systematic review and meta-analysis, 1998-2019. Arch Public Health. 2019;77:55.

13. Dulloo AG, Jacquet J, Solinas $G$, et al. Body composition phenotypes in pathways to obesity and the metabolic syndrome. Int J Obes. 2010;34(Suppl 2):S4-S17.

14. Kim EH, Kim HK, Bae SJ, et al. Gender differences of visceral fat area for predicting incident type 2 diabetes in Koreans. Diabetes Res Clin Pract. 2018;146:93-100.

15. Tuzun S, Cifcili S, Dabak MR, et al. Sarcopenia among genders in type 2 diabetes mellitus patients using different formulas of bioimpedance analysis. J Coll Physicians Surg Pak. 2018;28(8):586-9.

16. Solanki JD, Makwana AH, Mehta HB, et al. Body composition in type 2 diabetes: change in quality and not just quantity that matters. Int J Prev Med. 2015;6:122.

17. Zhao ML. The principle and the use of body composition measurement based on bioelectrical impedance analysis. Parenter Enteral Nutr. 2016;23(1): $50-4$

18. American Diabetes Association. Classification and diagnosis of diabetes. Diabetes Care. 2017:40:511-24.

19. Zhong JY, Wan Q. Correlation between waist-to-hip ratio with hyperglycemia, hyperlipidemia and hyperuricemia in physical examination population. Lab Med Clin. 2018;15(19):2848-51.

20. China overweight/obesity medicine nutrition treatment expert consensus writing committee. China overweight/obesity medical nutrition treatment experts consensus (2016). Diabetes World. 2016;10(9):395-8.

21. Zimmet $P$, Alberti KG, Shaw J. Global and societal implications of the diabetes epidemic. Nature. 2001;414(6865):782-7.

22. Stumvoll M, Goldstein BJ, van Haeften TW. Type 2 diabetes: principles of pathogenesis and therapy. Lancet. 2005;365(9467):1333-46.

23. Vos T, Barber RM, Bell B, et al. Global, regional, and national incidence, prevalence, and years lived with disability for 301 acute and chronic diseases and injuries in 188 countries, 1990-2013: a systematic analysis for the Global Burden of Disease Study 2013. Lancet. 2015;386(9995):743-800.

24. Ali MK, Bullard KM, Saaddine JB, et al. Achievement of goals in U.S. diabetes care, 1999-2010. N Engl J Med. 2013;368(17):1613-24.

25. Yang W, Lu J, Weng J, et al. Prevalence of diabetes among men and women in China. N Engl J Med. 2010;362(12):1090-101.

26. $\mathrm{Xu} Y$, Wang $L, \mathrm{He} J$, et al. Prevalence and control of diabetes in Chinese adults. JAMA. 2013;310(9):948-59.

27. Weinstein $A R$, Sesso HD, Lee $I M$, et al. Relationship of physical activity vs body mass index with type 2 diabetes in women. JAMA. 2004;292(10):118894.

28. Li X, Katashima M, Yasumasu T, et al. Visceral fat area, waist circumference and metabolic risk factors in abdominally obese Chinese adults. Biomed Environ Sci. 2012;25(2):141-8.

\section{Publisher's Note}

Springer Nature remains neutral with regard to jurisdictional claims in published maps and institutional affiliations.
Ready to submit your research? Choose BMC and benefit from:

- fast, convenient online submission

- thorough peer review by experienced researchers in your field

- rapid publication on acceptance

- support for research data, including large and complex data types

- gold Open Access which fosters wider collaboration and increased citations

- maximum visibility for your research: over $100 \mathrm{M}$ website views per year

At BMC, research is always in progress.

Learn more biomedcentral.com/submissions 